\title{
3. Studying Government by (Dis)Association
}

Methodologically, my approach to the governing of asylum is informed by a shift from social constructivism to enactment (Law 2004b). This is related to a twist suggested by actor-network theory (ANT) scholars, particularly Latour (2005) in his programmatic Reassembling the Social regarding the social and sociology. In this view, there is no society that precedes practice: no society outside the material-discursive practices in which it becomes enacted. Accordingly, the "social" as a denominator of processes of acts or entities loses its explanatory force. What this implies is a reversal of perspective: not to explain the construction of things with the social, but to trace how the social is assembled in practices in which heterogeneous "actants" (Latour 2005, 54-55) are involved. This also means: If things are constructed, a simple deconstruction of their existence does not account for the meticulous work their construction and stabilisation takes (Law 2009). This means to shift the focus from deconstruction to the how of construction (see Law 2004b). ${ }^{1}$

Relatedly, I do not approach asylum governance through 'big' explanatory categories such as the state, bureaucracy, or law not because I think they are not 'real', or 'only' social constructions. Rather I think they do not lend themselves to explain the practices of governing asylum very well: explanations that revert to features commonly attributed (for instance) to law to explain law (or vice versa) remain inevitably caught in a tautological dead-end (see Latour 2010, 255-56). Instead, I develop on STS and ANT perspectives and critical approaches to the state in human geography (Jeffrey 2013; McConnell

1 Some authors thus call the perspective associated with ANT research "post-constructivist" (e.g. Kneer 2009, 27). But I am not convinced of strategies that simply replace the old by adding a "post-" in front of it. I would rather cautiously retain some of the linkages with perspectives subsumed under "constructivism", while in some respects explicitly departing from them. 
2016; Mountz 2003; 2010; Painter 2006) and social anthropology (Gupta 1995; 2012; Li 2007; 2005; Mathews 2008). I suggest a form of analysis which takes social entities such as the state, bureaucracy, and law as effects (Mitchell 2002; 2006), not causes, of practices that need rather than offer explanation.

\subsection{Engaging the Dispositif}

An organization is (...) made only of movements, which are woven by the constant circulation of documents, stories, accounts, goods, and passions. (Latour 2005, 179) $)^{2}$

For operationalising the notion of the dispositif, I suggest a methodological approach I call "studying government by (dis)association" which may be applicable beyond the case of governing asylum. In the way Foucault used the notion, the dispositif does not simply lend itself to an empirical enquiry. The multiplicity of elements - things, people, discourses - composing a dispositif make it indispensable for me as an analyst to selectively cut across it and direct my and the readers' attention to some of its bearings. This approach sheds light on the "witches brew" (Foucault 1991, 81) of everyday practices at the heart of a dispositif's emergence and stabilisation: the practices of composition and cutting apart of relations, in short "practices of (dis)association". ${ }^{3}$ Such an approach to the dispositif not only highlights the fragility of government, but also allows us to grasp this fragility by revealing the "myriad associations required to keep it together" (Levi and Valverde 2008, 822) as well as the governmental need to omit, name, classify, distinguish, and resolve. The latter points to the "reality-constituting power" (Keller 2011, 14:8) of enacting the material-discursive arrangements of the dispositif.

2 The German version is somewhat more poetic: "Sogar noch weniger als der politische Körper ist eine Organisation eine 'Gesellschaft', denn sie besteht nur aus Bewegungen, die durch das ständige Zirkulieren von Dokumenten, Geschichten, Berichten, Gütern und Leidenschaften gewoben wird" (Latour 2007, 309).

3 To capture this central mode of operation, the dispositif thus could be called a "dispositif of winnowing" [Trennungs-Dispositiv], winnowing meaning "examination", "inspecting" and "sorting" but also "rejecting" in the sense of "sorting out" [ausscheiden] (see Bowker and Star 1999; Sauer 2015). 
Figure 2: Enactment, stabilisation, and effects of the dispositif

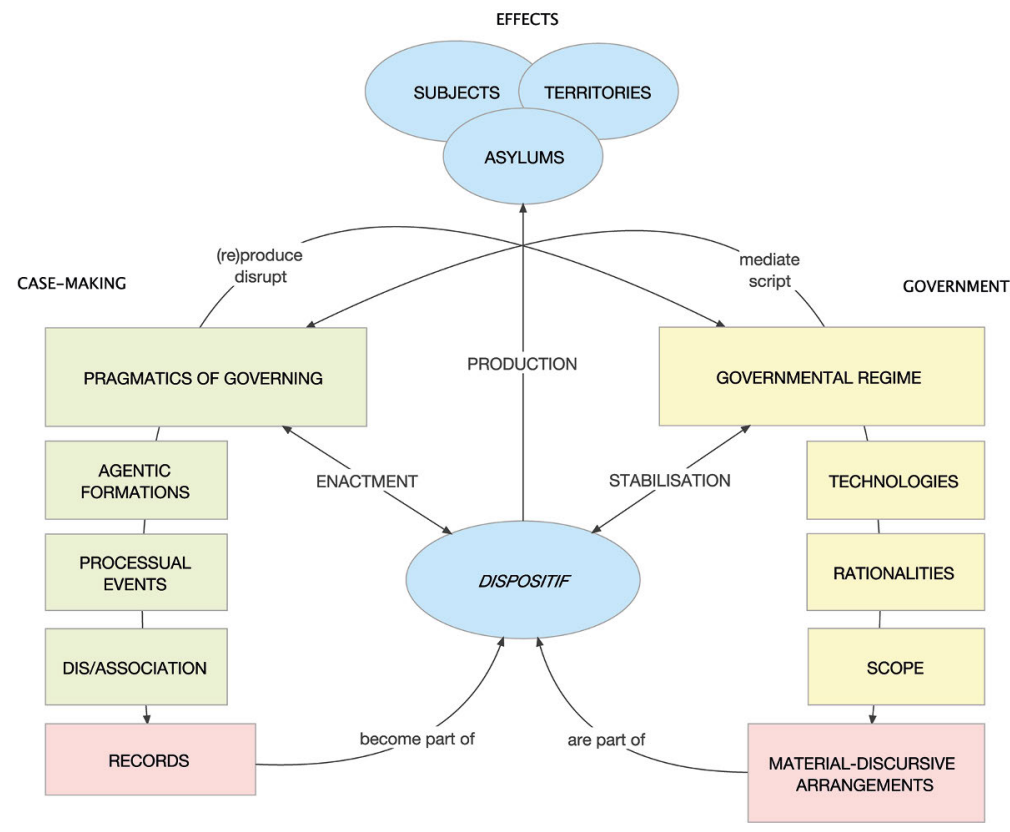

(Own illustration)

Figure 2 indicates how the different parts of my conceptualisation interrelate: the dispositif is enacted in pragmatics of governing - agentic formations which produce in processual events crucial (dis)associations that enter case files as records. This pragmatics of governing asylum is mediated and scripted by a governmental regime - technologies of governing (such as recording, calculation and standardisation) and rationalities (in the case of asylum: humanitarian discourses of protection, securitisation discourses of deterrence, but also bureaucratic discourses of efficiency). Such technologies and rationalities have a particular spatiotemporal scope - which is at the same time the scope of the dispositif (see also Valverde 2011). And they have a material-discursive form that influences the effect they have on the everyday practices of case-making. They coalesce in the form of material-discursive arrangements that mediate and script the pragmatics of governing. In turn, the pragmatics of governing are both reflexive and produce at times "overflows" (Callon, 1998) which means they are constantly involved in the 
arrangements' (re)production and disruption. As an effect, they produce asylum and its subjects and territories as material-semiotic webs.

Methodologically, my approach resembles what Mol (2002, 53-55) called "praxiography" (rather than "ethnography" as "cultural description", Van Maanen 1982, 103), as it is interested in describing the "'practicalities' of enacting reality". As she put it: "To be is to be related. The new talk about what is, does not bracket the practicalities involved in enacting reality. It keeps them present" ( $\mathrm{Mol} 2002,53-54)$. This both includes a strong emphasis on the relationality of being (Massey 2005), the mundane, prosaic practicalities (Painter 2006) and the productive power of practices of government (Foucault 2008). My 'field' in fieldwork is thus the dispositif of governing asylum and fieldwork meant engaging the dispositif: in short, assembling connections and attending to the "scaling, spacing and contextualising" (Latour, 2005 , 184) involved, i.e., entering its peculiar ways of seeing, and tracing limits of ways of thinking and doing.

\subsection{Methodological Maxims}

The first methodological maxim of this study is: I do not claim to provide a comprehensive or true account of how things work in the asylum office or of the 'asylum system'. First, from an ontological perspective, there is no one asylum system, but a multiplicity of systems and asylums depending on the instruments of "seeing" practices through the dispositif. ${ }^{4}$ This book is thus instead the result of my attempt of assembling a written version of the asylum dispositif at a particular conjuncture of my production of it. As Pottage (2011, 165) emphasised, "assembling a dispositif is a contingent and strategic theoretical operation". Research in this understanding is not passive, but generative of the realities it describes (see Law 2009). This means that by attending to and writing about the prosaic practices of case-making, I am involved in (re)assembling the asylum dispositif. It moreover takes you as a reader to reassemble it through your effort of imagination and bricolage. What Flyvbjerg (2001) said about his account of the Aalborg traffic planning process he studied is very much true for my account as well: "The case story ...

4 This follows Mol's (2002) insight on the body multiplying with each paediatric practice directed at it in a hospital. 
can neither be briefly recounted nor summarized in a few main results. The story is itself the result. It is a 'virtual reality,' so to speak, of politics, [and] administration" (Flyvbjerg 2001, 145). This "virtual reality" ideally complements - and at times unsettles - other stories of the 'asylum system' and its workings.

The second maxim is that an impartial or objective account of the asylum dispositif is epistemologically impossible. This is a central insight of feminist scholars about knowledge production: that all knowledge is partial in perspective and situated, related to the context in which it is produced (Haraway 1988; G. Rose 1997). Knowledge is moreover embodied, as feminists have long argued (Haraway 1988). They have overturned the myth of objectivity, of disembodied and dislocated knowledge, of the "god-trick" of "seeing everything from nowhere" (ibid., 581) and insisted "on the embodied nature of all vision" (ibid.). The notion of embodiment introduced a way to analytically grasp the important relationship between discourse and materiality in everyday practices of government (Mountz 2003; 2004). Feminist political geographer Mountz pointed out that "power moves through dis/embodiments, and it is therefore important to analyze who is embodied, how, and why in the relationship between the state and smuggled migrants" (Mountz 2004, 328). Through my own research practice of embodiment, I try to account for the ways in which knowing and enacting the asylum dispositif is embodied in mutable, sometimes contradictory ways. ${ }^{5}$

Importantly, both scientific and administrative practices of knowledge production are partial, situated and embodied. The partiality of my account has (at least) four roots: first, my (spatiotemporally) partial encounters with configurations of the dispositif; second, the partial presentations of configurations, rationalities, cases, and convictions to me as a researcher; third, my partial interpretations of encounters and representations; and fourth, my partial representation of these interpretations in this written account that also represents my multiple positionalities (of researching and doing casework, see next subchapter). Furthermore, the perspectives of my research subjects also remain partial, situated and embodied. They have their own evolving and situated positionalities and see the workings of the dispositif

5 Cood $(2007,237)$ however rightly pointed out that while "academic scholars can always evade responsibility by stressing the provisionality of their conclusions ... judges [and officials] have no such luxury". 
from these partial perspectives. Thus, my account of the dispositif assembles partial perspectives and ways of knowing from two distinct conjunctures: my own situated encounters with some of the people and things of the dispositif and the entanglement of those I met in the office with the dispositif. To add to this epistemological complexity, I cannot predict how you will read my account: it depends on your situated (and necessarily partial) ways of knowing and seeing. I can only attempt to persuade you "to understand differently, to articulate the linguistic constructions in such a way that they make a different kind of sense" (Massey 2003, 78).

\subsection{Assembling Research Achievements}

My analysis draws on a qualitative case study of asylum case-making in Switzerland. A brief personal account of fieldwork can be found in the Preface. In this subchapter, I introduce additional facets and considerations of my research approach. I conducted in-depth fieldwork in the Swiss asylum office, which is part of the State Secretariat for Migration (SEM) from autumn 2012 to summer 2014. I first participated in the basic training for newly hired asylum caseworkers. Then I spent "time on the inside" (Billo and Mountz 2016, 10-11) in one of five reception centres and two of eight sections in the headquarters of the SEM where asylum cases are processed. I followed asylum cases on their potential trajectories of assembling from their opening to their closure (Marcus 1995).

Recurrent negotiation of access in the administration meant transforming my role from a more-or-less-involved participant observer that consisted of "dwelling in the offices of the institution" (Billo and Mountz 2016, 11), to a more involved actor in casework as an unpaid intern in the second half of my fieldwork. Emphasising participation in everyday administrative life provided a wealth of insights in recurrent encounters with caseworkers and their superiors in dialogical or group settings (O'Reilly 2005, 103-4). Moreover, it exposed me to the thrills and anxieties of case-making. Additionally, I conducted a small number of in-depth qualitative interviews with caseworkers and superiors outside the office (six interviews lasting between 
one and three and a half hours that I tape-recorded and transcribed). ${ }^{6}$ Due to the emphasis on participation and interaction in my research, I tend to think of my fieldwork not in terms of passive data produced but in terms of "research events" (see Whatmore 2003, 97-99). This is not to conceal the fact that I had a concrete interest in producing research "achievements" (Massey 2003, 77). ${ }^{7}$ Yet it meant that my achievements mostly emerged in two-sided and unscripted encounters: in informal discussions with caseworkers, superiors, interpreters, and minute-takers, and at administrative events in which I participated.

My role in the field was a constant matter of negotiation and navigation. While I was often treated as a co-worker (even if a slightly unusual one, I assume), occasionally the other half of my double role surfaced and I was singled out as an observer, as "the one who is going to write about us". The ambiguous attributions I experienced in the office were reflected in my attempt to position myself as both a sympathetic, engaged participant of casework and a critical, distanced observer. This challenge of navigating closeness and distance and relations of power in the field has been discussed extensively amongst social anthropologists and geographers (Katz 1994; Mountz 2007). The role required continuous navigation and also involved thinking about reciprocity in research relations, which varied during the course of my fieldwork. In the basic training for new caseworkers, I was a 'normal' participant in a heterogeneous group of people from different units and locations in the office. My nametag, however, said "PhD Student, University of Zurich", which still singled me out as attending the training on a special 'mission'. During my fieldwork in the reception centre, I was mainly a silent observer in hearings and a sympathetic listener in encounters, questioning people about how they did things and how they arrived at their conclusions in concrete cases. My frequent presence at the reception centre was met with invaluable support but also a certain curiosity (if not suspicion) at

\footnotetext{
6 While I thus included multiple forms of data and perspectives of different parts of the asylum office, my research does not amount to genuine "multi-perspective" research as conducted by Achermann (2009) in her work on immigrant prisoners in Switzerland. In order to constitute multi-perspective research, my work would have needed to incorporate the perspective of asylum seekers subjected to the governmental regime.

7 I follow here Massey (2003), who took up Latour's decentring of "data" by acknowledging its active production, and thus calling it the "achievement" of research practices (involving researchers and the researched) instead of data.
} 
times. While in this first research phase, I still tried to achieve maximum breadth in my sampling regarding whose hearings I attended, with whom I talked, and into what kind of cases I could get insights. There remains a crucial bias that emerged from the research ethics regarding the question of participation. Certain caseworkers started inviting me to their hearings or asked me to accompany them for lunch. They also mentioned that it was insightful to discuss their work with someone from the outside, and that talking intensely about their cases was revealing for them. As a caseworker told me in this respect: "you learn with every case that forces you to think through the procedure" (Fieldnotes, reception centre, spring 2013). Others remained more reluctant concerning my research, and I accepted this. The first are therefore clearly overrepresented in my fieldnotes.

In the second part of my fieldwork that brought me to the headquarters, I became more involved in casework with a stronger emphasis on participation than observation (O'Reilly 2005, 105-9). The deal negotiated with my key officials was: in exchange for some work as a peculiar intern, I could participate in the office life of two different sections of the headquarters - one section in each of the two divisions - for an extended period of three months in each. This shift in my involvement in practices came with an ambiguous effect for my research. On the one hand, my access to 'data' in the office was extended tremendously: in accordance with my data protection agreement and my superiors, I could order case files relevant to 'my' cases from the archive to study, trace the status of cases I had encountered in the reception centre through the internal migration database, or I could access guidelines and internal sources of knowledge for decision-making. Moreover, I received an institutional email account and received all the information sent around to some of the distribution lists. On the other hand, my research slowly but steadily lost significance compared to the tasks I was attributed and that marked me a 'productive' collaborator in the sections. Of course, everyone still knew I was doing research, but people rather started treating me as a novice employee (like others in the sections where I was working at the time). I struggled to navigate between the two roles. As much as I lost confidence in my research endeavour, I gained recognition for the new administrative tasks I had adopted. To the extent that I was enrolled in the dispositif's enactment, I came to embody it in my own terms: I spoke the "language of stateness" (Hansen and Stepputat 2001, 37) in legal and institutional terms, and I was drawn into collectives enacted in the practice of doing casework, namely by conduct- 
ing hearings or drafting decisions. Methodologically, this process of embodiment and immersion was nevertheless crucial for my scientific account of the dispositif, as it provided an "intimate familiarity" with its workings and reshaped my perspective: "The researcher's intimate familiarity with and insight into these [organizational] actions are what is required for theorizing, because organizational learning is as much about act and artifact and their meanings as it is about cognition" (Yanow 2003b, 47). By opening up my field of research to work experiences of myself, I gained access to more intimate "worlds of sensibilities, passions, intuitions, fears and betrayals" (Law 2004a, 3), but in turn I exposed myself to the ethical quandaries that come with more active involvement in doing casework. Considering the power relations and ethics of this engagement, the whole account I give here should bear testimony to my notion of field research as a "two-way engagement":

If you take a position that the world out there, or more specifically your object of study, can speak back, that it too is an active agent in this process of research, then what is at issue is a real two-way engagement. Many imaginations of the field have pictured it as static, as synchronic. A revision of that imaginary would make the field itself dynamic; and it would make fieldwork into a relation between two active agents. It would recognize it as a two-way encounter. (Massey 2003, 86)

In short, the field worked on me as much as I worked on the field. Concerning the ethics of doing casework, I ended up in a balancing act to reconcile my own ethical standards with the institutional requirements (in which I was not alone; see subchapter 8.1). Overall, achievements of my fieldwork in the asylum office include fieldnotes from participant observation and observant participation in different sections processing asylum cases and from informal conversations (both verbatim and paraphrased), transcripts from a few interviews with caseworkers and heads of sections, and a collection of organisational documents, including protocols from asylum hearings and other case-documents. ${ }^{8}$ In my analysis, I have thus triangulated such different forms of data (Flick 2008).

8 These notes include about 450 pages of fieldnotes, 320 pages of interview transcripts, 60 case files (of which 6 are female applicants and 7 are families), and uncounted administrative documents such as guidelines, $\mathrm{COI}$ documents, handouts and meeting protocols. 


\subsection{Reassembling the Dispositif}

The achievements of fieldwork introduced above materialised in the form of fieldnotes. In the hearings and organisational events in which I participated, I had notebooks with me and instantly wrote notes. In the workplace environment (in the corridor, the printer room, other people's offices, or coffee and lunch breaks), I mostly jotted down conversations after having returned to my desk. I usually turned the textual fragments - the notes, scattered jottings, and key words - of the day into full-fledged fieldnote texts "as accurate[ly] as memory and ear allow[ed]" (Van Maanen 1982, 105) in spare hours in between or during my evening commute (see O'Reilly 2005, 98). It was also in these moments that I wrote "memos" with preliminary interpretations, links to theory or open questions and issues to be addressed in the further fieldwork (Strauss and Corbin 1996, 169-72). The content of fieldnotes from the more participative second part of my fieldwork are different from those of the first part: they are less concerned with hearings and cases, mostly capturing conversations I had with people in the corridor, in coffee or lunch breaks, and notes from the training I received to do my new tasks. And they increasingly describe my own work and my reflections of it. I am aware of the fact that my research practice in some respect mimics bureaucratic work: it consists of documenting an empirical phenomenon by protocolling conversations, collecting documents as well as various ordering, naming, and representation practices. As Riles $(2006,7)$ pointed out, "documents are artifacts of modern knowledge practices, and, in particular, knowledge practices that define ethnography itself". Documentation is thus pervasive both in bureaucratic and ethnographic practice - and as an "epistemological model" (Ginzburg 1989, 101 cited in Riles 2006,6 ) it entails a particular interpretative gaze, which requires some reflection.

Although the materials produced in fieldwork are rather "achievements" than data, they are far from mere "findings". It is a laborious process to assemble insights or theory (as a form of grounded theory) from field material: what is usually referred to as "analysis" involves ordering, disciplining, transforming and translating it into a story. As Crang $(2003,127)$ puts it: "making sense is a creative process". Moreover, I agree with Crang that the usual distinction between activities of analysis and writing up is misleading: "Analysis is not simply an issue of developing an idea and writing it up. Rather, it is thinking by writing that tends to reveal the flaws, the con- 
tradictions in our ideas, forcing us to look, to analyse in different ways and rethink" (Crang 2003, 130). I started making sense of what I saw and heard in the office during my fieldwork periods and used memos to keep track of those thoughts or raise open questions and things to track. And during all phases of my research project, I invested extended periods in reading a broad range of scientific papers and books to deepen my "theoretical sensibilities" (Strauss and Corbin 1996, 25-30). I adopted approaches from content analysis (Mayring 2010) to code and categorise the interview transcripts and the spoken parts of fieldnotes. I used the qualitative data analysis software MaxQDA for this purpose. But as I was also interested in the reality-producing discourses and rationalities that orient case-making, I moreover drew on discourse analytic approaches (Hajer 2004; Keller 2008). The translation of research "achievements" into "insights" was thus a long and arduous process, one that is not finished yet.

Overall, my analysis centred on the dispositif, which I tried to reassemble through the tracing of material-discursive associations, enabling - and produced in - practices of case-making. I thus approached my material through my (evolving) theoretical lens, but in turn developed conceptualisations in light of empirical material. My reassembling of the dispositif takes the form of "situational herbaria": the displaced yet still contextualised readings of my encounters with cases, practices and people in the office. ${ }^{9}$ I followed Walters' (2015, 6, own emphasis) suggestion to "give more weight to what we could call mid-range concepts" to make sense of governmental practicalities or rationalities in a domain such as governing asylum. In each of my situational herbaria, I thus postulate a mid-range concept for making sense of facets of governing asylum. I have, for instance, introduced the notion of "exemplars" to grasp ways of knowing (Chapter 4), various forms of "devices" that contribute to agentic formations (Chapter 5), or "processual events" to make sense of the pragmatics of case-making (Chapter 6). Such concepts may offer insights beyond the confines of the empirical example in which they are raised. But they are not so wide-ranging as to, for instance, explain what governing asylum is all about. Moreover, adopting sensibilities from careful qualitative geographic and ethnographic approaches has allowed me to analyse asylum governance "beyond a concern with singular logics and look for unexpected, paradoxical, heterogeneous and perhaps unstable combinations of rational-

9 The credit for this notion goes to Anna-Katharina Thürer. 
ities and techniques" (Walters 2015, 6). In the long, iterative analysis process, I found myself, as Crang (2003) indicated above, shifting between bits of text I was writing, things I remembered from my fieldnotes, interviews or cases, and ideas and conceptualisations from the literature: a lot of the process usually called analysis was thus "thinking through writing and rewriting".

I feel compelled to make a few remarks about the role of (theoretical) arguments in such a "scientific analysis" and the unescapable politics of representations. First, I began to realise in the years of my travelling on bureaucratic and legal tracks that arguments - be they legal or scientific - are not passive. They do important work: they are "performative accounts" (Introna $2013,340) .{ }^{10}$ For instance, there are arguments in asylum proceedings that serve to dismiss life experiences of applicants as irrelevant. They act as a filter for what exists and what does not. In other words, they are truth claims that reframe truth, (seemingly) in contrast to other accounts, serving as a form of "veridiction", of truth-telling (Foucault 2014a). But the two forms are intimately related - if an argument is embedded in the authorising (material-discursive) nets of 'science' or 'law', reframing is quickly tantamount to production.

Second, the ways in which arguments operate crucially depends on the cosmological frame in which they are enunciated. In other words, it matters what both the enunciator and the audience believe the world is made up of - both ontology and ethics meet in arguments. This claim builds on Fleck's $(1979,35)$ famous rethinking of scientific knowledge in his insight that knowing is always dependent on the "thought collective" in which it is situated. To make an argument is thus usually a matter of heartfelt or intimate conviction that does not need to be made explicit as long as the argument does not leave the "thought collective" in which it makes sense. This is related to a third point: an argument's potential to act arguably derives from the associations it is able to establish, for instance from references to other authoritative texts (scientific literature) or as means of quantification. Yet, ultimately, no argument escapes the politics it is involved in.

Haraway has raised this crucial concern about scientific knowledge production in an interview (Penley, Ross, and Haraway 1990), in which she distinguished between "two simultaneous, apparently incompatible truths" (ibid., 8) that "practices of the sciences" (ibid.) entail. The first truth refers

10 I am aware of the paradoxical undertaking of arguing about the nature of arguments. 
to the historically and culturally specific production of scientific knowledge, rendering it "radically contingent". The second truth points to the fact that scientific knowledge production is political: "there are political consequences to scientific accounts of the world" (ibid.). But in itself, Haraway insists, scientific knowledge can be both subjugating and liberating. Thus, I feel a responsibility that the liberating facets of the stories I tell will prevail in the reception of my work.

If this book is a place (in the sense of Massey 2005) where histories meet, they met because I made them do so. For this reason, I feel a need to acknowledge a violent displacement of situated statements (that arose in particular and often personal encounters) into a scientific text where they are supposed to do something: to speak for me, the researcher, to support my argument, to indicate or show something. Telling stories is a matter of power, as Nigerian writer Chimamanda Ngozi Adichie lucidly pointed out in her talk "The Danger of a Single Story": "How they [stories] are told, who tells them, when they're told, how many stories are told, are really dependent on power" (Adichie 2009). Adichie added, "power is the ability not just to tell the story of another person, but to make it the definitive story of that person" (Adichie 2009). These statements resonated very much for me with how asylum decisions tell a single story, from one perspective, which becomes in a powerful and potentially violent way "the definite story of that person". In what could be considered an ironic twist, my account of officials' stories and the accounts that caseworkers write of asylum seekers' stories can be found guilty of generating some of the same disempowering effects for those written about. Both accounts involve a displacement of the statements from the situation in which they were uttered and a narrative displacement: they are stripped of the narrative context in which they were uttered. Of course, I do not want to imply that the consequences of both accounts are in any way comparable. Rather, I would like to acknowledge some of the remarkable yet at times frightening parallels of legal and scientific renderings of the world. ${ }^{11}$

11 Becker and Clarke $(2001,18)$ suggested these parallels between legal-bureaucratic and scientific styles to be pronounced: "It has become clearer that the self-proclaimed rhetoric-free writing of our modern science and academia is simply its own rhetoric: the plain or mechanical or bureaucratic or other modern style, and their related tropes, figures, énoncés and microtechniques of visualization, such as images, lists, charts, schemata, tables, and graphs. The use of such devices unites science and academia seamlessly with bureaucracy". 
While the story this book tells about the asylum dispositif of course does not claim to be the definitive one (see Flyvbjerg 2001), it is nevertheless a rare and therefore potentially significant story for those whom I write about. I therefore tried to multiply stories and perspectives through various modes of engagement with the people, practices, and technologies of case-making, but also through my attempts of decentring what I experienced from its obvious interpretation. This is my way to cope with the difficulties associated with a single story.

\subsection{Ethics of Engaging in Casework}

Data protection and anonymisation were crucial issues in this research project. On the one hand, they were crucial for legal reasons and negotiating access to the administration; on the other hand, they were crucial for ethical reasons, even though the differences in hierarchical positionings of researcher and participants were not as problematic as in other geographical areas of work (see Kaspar and Müller-Böker 2006, 127-28). In order to gain access to the administration and conduct fieldwork, I had to sign a data protection declaration written by the legal division of the migration office. ${ }^{12}$ It stated that the directives on data protection, the principle of public access of the administration, and information and IT security to which officials were bound applied to me and my work inside and beyond the administration. It moreover explicitly raised the issue that personal data obtained during my research are only to be used for the purpose of the study and only to be made public with the consent of the office. Moreover, outcomes shall be published in a way that the persons concerned are not identifiable. The last points well overlap with data anonymisation concerns from a scientific point of view that participants should face no personal disadvantage as a result of what they shared with me. I realised anonymisation by either simply indicating the role of the participants or by using a pseudonym (Kaspar and MüllerBöker 2006, 139). While this limits the reader's understanding of the participants' positionality (for instance, in terms of gender or professional background), it also limits misleading inferences readers may have made if such

12 The legal division examined all texts, including this monograph, and verified compliance with the declaration before publication. 
highly selective information about participants were provided. Data protection also prohibited disclosing internal or confidential administrative documents or practices.

My research further dealt with the question of consent in two regards (Kaspar and Müller-Böker 2006, 129): consent of the research participants officials (including caseworkers) - and also consent of the other, more vulnerable participants of research encounters - asylum applicants in the hearings. For the first type of participants, the degree of consent varied between formal interviews (high), informal group settings (medium), and 'duties' (low). While for interviews, consent was simple to achieve, in informal group settings, it was often implicit by officials' choice to either talk to me in coffee or lunch breaks or simply avoid me. In instances of 'duties', where the superiors, for example, instructed caseworkers to show me some sort of specific information, consent was marginal. However, caseworkers could treat me in these cases with professional distance. The asylum applicants in the hearings I attended were usually asked at the beginning of the hearing about their consent of my presence. In other cases, I was introduced to them as "a member of the office in training". In the former case, the consent is arguably rather of theoretical nature in the setting of an official hearing: no applicant ever said "no". Fortunately, my presence rather had the reverse effect than what Van Maanen (1982) experienced in the police squad he accompanied in his ethnographic research. While his policemen turned more vicious and brutal to prove to the researcher their sovereignty in the streets, the caseworkers I observed seemed inclined to treat applicants decently and in accordance with the quality criteria for asylum hearings in my presence.

My own involvement in casework makes it crucial to explicitly discuss some of my reflections here. What exactly was I involved in? During the last phase of fieldwork, I drafted about two-dozen decisions on applications for family reunification. I drafted five decisions on asylum applications in close collaboration with experienced caseworkers and the head of the respective section. I conducted three hearings, two of them in a 'training situation', i.e., with another caseworker attending and intervening at times. I tried to conduct the three hearings as conscientiously and fairly as I would wish them to be if I had to apply for asylum myself. In the decision drafts I wrote, I had to balance my personal ethical notion of justice with the office's principles and the legal scope: I used my discretion to provide protection where my coaches approved of it. In one instance of an application for family reunification, I 
returned the case to the head of section because I could not live with writing a rejection. (It was legally clear in the eyes of the senior official, but morally too wrenching to do.)

I did not take the decision to engage this way in casework lightly. I wasn't the only 'ghost-like' worker in the administration - there were the so-called "poolies": people hired on an hourly wage just to conduct hearings (some of them university students); and there were also other "hidden decision-writers', people temporarily hired to write "simple" decision drafts on the basis of hearing protocols under the guidance of heads of sections. Furthermore, most people who were trained with me in my first fieldwork phase started doing casework soon after, while I had dwelled on approaches to case-making for quite a while before becoming active. Lastly, as a Swiss citizen, I am always complicit in the granting and rejecting of applications in the asylum office, since I am part of the democratic collective who has delegated such difficult "life and death decisions" to institutions (Douglas 1986, 111). As Douglas $(1986,111)$ pointed out, citizens of Western nation-states tend "to leave the important decisions to ... [their] institutions". While these considerations comforted me during difficult moral choices that I made, they do not remove my responsibility for them.

\subsection{Notes on the Possibility and Conditions of Critique}

Our argument has been that methods are never innocent and that in some measure they enact whatever it is they describe into reality. Social science methods are no exception. (Law and Urry 2004, 403)

If scientific engagements produce realities, we cannot avoid the question: what sort of realities do we want? In response to this question, authors with a material-semiotic perspective have suggested possibilities to account for the specific "ontological politics" (Mol 1999) of practices. Haraway's (1991) trope of the cyborg recasts feminist politics at the intersection of science fiction imaginary and material reality and encourages us to envision "transgressed boundaries, potent fusions and dangerous possibilities" (Haraway 1991, 295). Law (2004a; 2009) suggested methodological tools "for partial connection" (Law 2009 , 154) to avoid reductionist representations of different version of the real. If we acknowledge that innocent research is impossible, a careful 
engagement with its ontological politics becomes paramount (Law 2009, 155). It moreover accounts for the controversies over what is desirable and condemnable from the point of view of those governing asylum: $:^{13}$ who and what is admitted the status of the real, and how do actants reconcile overlapping realities (see Law 2009, 153-54). To understand how the multiplicity of interpretations of legal notions can be reconciled, I introduce the notion of the boundary object (Bowker and Star 1999, see section 7.2.2).

Negotiating field access meant that I was not only authoring the account at hand, but also accounting for my research 'in the field'. The research programme I had designed was in turn mediated by my encounters with key persons. At various occasions, I introduced my research project, most commonly in everyday encounters with caseworkers and other people in the office with a sort of elevator pitch about what my research was about. But I also recurrently explained it in front of seniors by using short texts outlining my research, or by incorporating first insights or at least 'hypotheses' about how I thought things really worked after having done fieldwork. I always felt uneasy about the latter type of texts, because that was not exactly what I thought I was able to provide. And they sometimes saw "explosive matters" in the theses I offered. For example, I had once suggested that "interpreters have a central role - both as producers of text but also as mediators and 'business card' of the office vis-à-vis the applicants". Yet this met with a strong response:

Your first hypothesis touches an explosive political issue: that you write "interpreters have a central role"... Their influence on the decision is only marginal, even though there are isolated situations of exceeding their competence. In the view of the office, they are mere tools. (Fieldnotes, reception centre, spring 2013)

It did not seem all too daring in light of the scientific literature to mention the significance of interpreters in asylum adjudication (Dahlvik 2010; Pöllabauer 2005; Scheffer 1997; 2001). But as the senior official who commented on it rightly pointed out, it clashed with the "view of the office" in which interpreters were neutral "tools". Furthermore, as he explained, occasional

13 It is indeed equally important to consider the moralities of those subjected the governing of asylum. However, this is beyond the scope of my study. 
faux pas occurred, but these only confirmed the usually unproblematic work of interpreters as intermediaries (see Latour 2005).

To develop both somewhat novel scientific insights and provide the asylum office with a critical yet sympathetic reading of their work seemed an increasingly impossible task: the two audiences' standards and expectations appeared to be too different. I remember that in my negotiations of field access with two senior asylum office officials, I suggested my research could provide an "outside view" of their work. They agreed but one of them emphasised that it needed to be "a professional, not a naïve outside view" (Fieldnotes, meeting, December 2012). What I think they alluded to is that a view "from the outside" could only be taken seriously in the office if it came from a position of knowing what casework means in practice. In retrospect, the idea of an outside view appears to me disputable in itself: At the end of my first meeting with them, I mentioned the difficulty of bridging theory and practice debates. In response to that, they pointed out the general theory aversion of the office - "people usually only want to know what is relevant for practice" (Fieldnotes, meeting, July 2012). In my view, however, theory and practice could not be as easily dissociated as their comment suggested: practice relies on the knowledge and associated technologies that build upon a set of interrelated premises, i.e., theory (see also Schatzki 2001). People working in the office are, of course, reflexive about such premises upon which their practices rely. They at times shared with me their own doubts and critical considerations about these premises. Some of these premises - convictions and rationalities - are discussed in the third part of this book.

In what sense, then, can I still engage the dispositif through my writing? I suggest that I can engage it through my notion of the dispositif as being about applicants' cases and how their lives are re-corded through them, as well as about caseworkers' interpretations of (and their occasional resistance to) 'the system'. As the irritation of the section head regarding my "theses" about the role of interpreter revealed, reassembling the workings of the dispositif has the potential to unsettle official perspectives or well-established convictions about how things are. My peculiar reassembling of the dispositif in this book's account does just that: It involves pondering the question of agency usually taken for granted (Part I); it shows how the pragmatics of case-making coalesces around a number of key "processual events" (Scheffer 2007a) and involves some key devices (Part II); and it highlights the caseworkers and senior officials' convictions and rationalities of their work jux- 
taposed against my own convictions about them (Part III). This means that my account in itself is political, as it provides an unfamiliar representation of governing asylum. My account thus practices critique in the sense Foucault (1988a) thought of it: through decentring all-too-common modes of thinking about asylum governance. As Foucault put it nicely:

A critique is not a matter of saying that things are not right as they are. It is a matter of pointing out on what kinds of assumptions, what kinds of familiar, unchallenged, unconsidered modes of thought the practices that we accept rest.... Practicing criticism is a matter of making such facile gestures difficult. (Foucault 1988a, 154-55)

If explicit critique is found in my account, it is in the third part. It is not primarily my critique, but critique I encountered and sometimes provoked in conversations and assembled on my way through the dispositif. The way I present it, however, turns it into my critique as well. 
